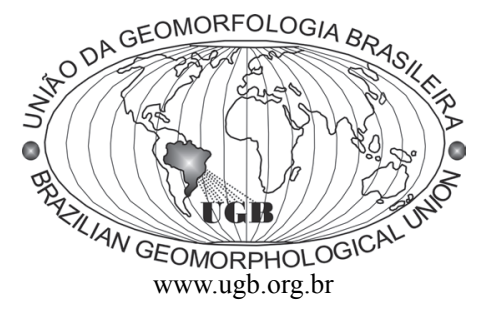

Revista Brasileira de Geomorfologia - v. 12, no $3(2011)$

\title{
IDENTIFICAÇÃO DE ÁREAS POTENCIAIS AO MAPEAMENTO DE TRILHAS ECOTURÍSTICAS NA PROPRIEDADE DO ECOPARQUE, EM CANELA/RS
}

\author{
Lia Lütz, Kroeff \\ Afiliação: Marion Lutz Kroeff e Carlos Alberto Kroeff - Endereço: Universidade Federal do Rio de Janeiro - \\ Departamento de Geografia - Av Athos da Silveira Ramos, 149. Prédio do Centro de Ciências Matemáticas e da Natureza \\ - Bloco F, Ilha do Fundão - CEP 21.941-909 - Rio de janeiro/RJ - e-mail: liakroeff@hotmail.com \\ Roberto Verdum \\ Afiliação: Agenor Verdum e Elnir Vieira Verdum \\ Endereço: Universidade Federal do Rio Grande do Sul - Instituto de Geociências- Departamento de Geografia - Av. \\ Bento Gonçalves, 9500 - Prédio 43136, sala 216 - CEP 90.509-900 Porto Alegre/RS - e-mail: verdum@ufrgs.br.
}

\begin{abstract}
Resumo
A principal atividade do ecoturismo, a caminhada em trilhas, deveria estar em consonância com os dois preceitos centrais do ecoturismo, ser uma atividade de baixo impacto ambiental e proporcionar aos seus praticantes a experiência e o aprendizado da natureza. Porém, corriqueiramente, as trilhas tornam-se apenas meios de deslocamento mais rápidos a atrativos de grande valor estético, não se aproveitando as potencialidades do ambiente. O objetivo deste trabalho foi elaborar uma proposta metodológica capaz de facilitar a identificação das áreas mais propícias à implantação de trilhas ecoturísticas. O estudo foi desenvolvido em uma área-chave, o Ecoparque, situado na área frontal da Cascata do Caracol, no município de Canela/Rio Grande do Sul (RS). A definição de Unidades de Paisagem (UP) demonstrou ser o método mais adequado para a identificação das áreas mais propícias por facilitar a identificação das áreas de maior fragilidade ambiental e potencial turístico, e a geomorfologia o critério mais apropriado para a delimitação das unidades. Os levantamentos de campo e o desenvolvimento de um Sistema de Informação Geográfica (SIG) forneceram informações essenciais à caracterização das unidades. Os resultados das análises realizadas permitiram o mapeamento de duas trilhas ecoturísticas.
\end{abstract}

Palavras-chave: Trilhas; Unidades de Paisagem; ecoturismo.

\begin{abstract}
The main activity in ecotourism, the hiking trails, should be in consonance with the main ecotourism principles, being a low impact activity and providing nature experience and learning. Although usually the trails become only a crosscut to everyday use, instead of a way to activate the most beautiful attractive of the place. The aim of this work was to develop a methodology that would facilitate the identification of the proper location and construction of trails. This methodology should avoid or minimize the tourism impacts, providing the best tourism potential. The study was conducted in the Ecoparque, the front area of Caracol Waterfall, located in the south of Brazil, Canela/Rio Grande do Sul (RS). The definition of the landscape units seems to be the best method to identify the proper areas to implant the trails. Geomorphology was the most important criteria on the units delimitation, once it helps to identify the most sensitive areas and the areas with most tourism potential. The field data and the GIS development give good information to characterize the units. With the large environmental information analyzed it was possible to map two trails.
\end{abstract}

Keywords: Trails; landscape units; ecotourism. 


\section{Introdução}

O ecoturismo é o segmento da atividade turística que apresenta, atualmente, o maior crescimento, o que resulta no incremento das ofertas e demandas por destinos ecoturísticos. Segundo a International Ecotourism Society (TIES ${ }^{1}$ ), o ecoturismo em 2004 já crescia em âmbito global três vezes mais rapidamente do que a indústria do turismo como um todo. $\mathrm{O}$ Instituto de Ecoturismo do Brasil (IEB ${ }^{2}$ ) estima que o movimento financeiro da atividade tenha quase quadruplicado de 1995 a 2005. De acordo com a definição de Fennel (2002):

\begin{abstract}
"O ecoturismo é uma forma sustentável de turismo baseado nos recursos naturais, que focaliza principalmente a experiência e o aprendizado sobre a natureza; $\dot{e}$ gerido eticamente para manter um baixo impacto, é não predatório e localmente orientado (controle, beneficios e escala). Ocorre tipicamente em áreas naturais, e deve contribuir para a conservação ou preservação destas" (FENNELL, 2002, p. 52-53).
\end{abstract}

$\mathrm{O}$ crescimento do ecoturismo está intimamente ligado aos destinos desta prática. Com o aumento da demanda, proprietários de áreas rurais veem no ecoturismo uma alternativa de ganhos financeiros e de utilização da área - muitas vezes restringida pela maior rigidez da legislação ambiental. Costa e Xavier da Silva (2004, p. 67) ressaltam que as Unidades de Conservação têm aproveitado seu potencial ecoturístico como uma alternativa de viabilidade econômica, a fim de manejar e administrar adequadamente essas áreas. A grande ânsia por ganhos econômicos suscita, muitas vezes, um desleixo do planejamento da atividade. O planejamento teria como objetivo geral avaliar as potencialidades turísticas de um ambiente e minimizar os impactos ambientais da atividade.

Atualmente, uma das principais atividades em ecoturismo é a caminhada em trilhas e suas variantes. Porém, corriqueiramente, as trilhas tornam-se apenas meios de deslocamento mais rápidos a atrativos de grande valor estético, não se aproveitando as potencialidades do ambiente. A trilha ecoturística não é somente um meio de deslocamento, mas o próprio destino da caminhada. As trilhas são uma oportunidade de maior contato com a natureza, de descoberta de novas paisagens e de seus processos ambientais. No entanto, dificilmente elas são implantadas e manejadas de forma a propiciarem aos seus usuários o traçado mais seguro e de maior prevenção aos impactos ambientais conjuntamente com a apreciação dos melhores atributos da paisagem.

O planejamento do ecoturismo deveria ter como foco de trabalho a avaliação das potencialidades e das fragilidades ambientais da área analisada, a fim de definir o traçado ideal

1 Disponível em: www.ecotourism.org/, acesso em 20 de outubro de 2007.

2 Instituto de Ecoturismo do Brasil. Disponível em: http://www. ibama.gov.br/revista/, acessao em 20 de outubro de 2007. das trilhas ecoturísticas. Este englobaria as áreas de baixa fragilidade ambiental e de grande potencial turístico, com o propósito dos ecoturistas terem o proveito máximo da área visitada, mas causarem o menor impacto ambiental, uma vez que se buscaria conduzi-los aos locais de grande atratividade através de ambientes menos frágeis. Dessa forma, se definiria as áreas com maior necessidade de preservação, de conservação, preparo de trilha e controle do número de visitantes.

\section{Objetivos}

O objetivo geral deste estudo foi elaborar uma proposta metodológica capaz de facilitar o planejamento de trilhas ecoturísticas, visando ao menor impacto ambiental e ao maior potencial turístico. A fim de que o objetivo geral fosse atingido, estipulou-se que a metodologia deveria atingir os seguintes objetivos específicos:

Caracterizar os aspectos ambientais da área de estudo; Gerar um Sistema de Informação Geográfica (SIG) do Ecoparque;

Definir as Unidades de Paisagem (UP);

Avaliar as áreas mais propícias à implantação de trilhas ecoturísticas, mediante a identificação das áreas de fragilidade ambiental e de potencial turístico;

Determinar os traçados mais adequados das trilhas ecoturísticas.

\section{Área de estudo}

A elaboração desta proposta metodológica se deu em uma área-chave (gleba) situada na área frontal da Cascata do Caracol, principal atrativo turístico do município de Canela/ Rio Grande do Sul (RS). A propriedade se localiza na região turística da Serra Gaúcha, ao Norte do Estado do Rio Grande do Sul, a aproximadamente $6,5 \mathrm{~km}$ ao norte do município, conforme Figura 1. Ela possui cerca de 375 hectares e características ambientais propícias ao desenvolvimento deste estudo, principalmente por ainda não possuir nenhuma trilha ecoturística implantada.

\section{Referencial teórico e conceitual}

De simples meio de deslocamento, as trilhas surgem como um novo modo de contato com a natureza; oferecem aos visitantes a oportunidade de desfrutar de uma área de maneira tranquila e alcançar maior familiaridade com o ambiente. Além disso, as trilhas bem construídas e devidamente mantidas protegem o ambiente do impacto do uso e, também, asseguram aos visitantes maior conforto, segurança e satisfação. 


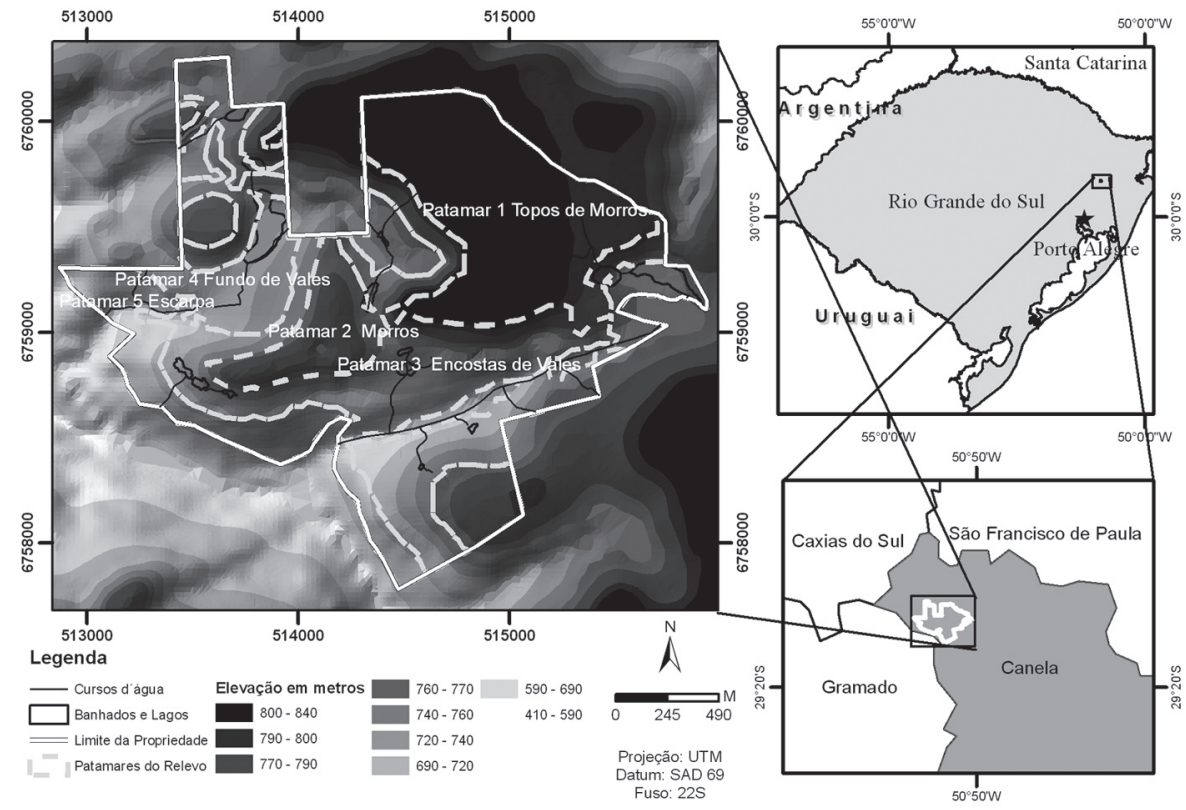

Figura 1 - Localização da área de estudo, Mapa hipsométrico e dos compartimentos do relevo

Normalmente as trilhas conduzem a um atrativo específico de alta beleza natural. A avaliação da beleza das paisagens é bastante subjetiva, mas alguns autores o fizeram a partir dos seus valores estéticos. Oliveira \& Griffith (1987, apud FAGUNDES et al, 2006) combinaram as variáveis alcance e magnitude da visão (posição do observador), visão de água e qualidade estética dos diferentes tipos de vegetação para avaliar os atrativos do Parque Florestal Estadual do Rio Doce. Conforme destacou Hart (1986, apud GUERRA e MARÇAL, 2006, p. 44) "muitas características que fazem de uma paisagem um local atrativo são geomorfológicas". Guerra e Marçal (2006, p. 44) argumentam que a geomorfologia "pode dar a sua contribuição na avaliação estética de uma determinada porção da superfície terrestre e isso é de grande apreciação pelo turismo, sendo um dos seus objetivos atrair os visitantes para admirar os diferentes cenários de uma região específica”.

No entanto, muitas vezes para se chegar aos atrativos turísticos, as trilhas passam por áreas de alta fragilidade, por possuírem maior propensão a impactos ambientais. Conforme Spörl (2001), a intensidade dos impactos depende do grau de suscetibilidade à mudança do próprio sistema e do esforço (ou tensão) aplicado nele pelo homem. Muitos impactos negativos podem ser reduzidos ou eliminados com o conhecimento dos processos que atuam na área de implantação e uso das trilhas. Ou seja, as áreas de maior fragilidade ambiental sofrerão as consequências danosas da ação antrópica mais rápida e intensamente.

As áreas sensíveis e principalmente as com potencial turístico serão mais facilmente mapeadas e definidas se estiverem embasadas na prévia compartimentação do terreno. Uma forma de compartimentar o terreno é mediante a definição de Unidades de Paisagem (UP).
As Unidades de Paisagem são unidades espaciais definidas por características singulares que as delimitam e as distinguem das outras unidades e permitem a introdução de critérios diferenciados de planejamento/gerenciamento ambiental. As Unidades de Paisagem podem ser delimitadas por vários critérios, a escolha dependerá dos objetivos do trabalho. Neste estudo, a geomorfologia foi o critério mais importante para a delimitação das unidades, pois, através da caracterização das formas do relevo, dos processos atuantes, da declividade e da hipsometria, foi possível verificar as áreas de maior fragilidade ambiental e potencial turístico para a instalação das trilhas.

\section{Metodologia}

A fim de se atingir os objetivos gerais e os específicos traçados, desenvolveu-se uma metodologia que tivesse como base o cumprimento dos preceitos do ecoturismo, ser uma atividade de baixo impacto e possibilitar a experiência sobre a natureza. Para tanto, foram aplicados métodos de levantamentos de dados em campo e armazenamento - pela criação do SIG (Sistema de Informação Geográfica) - e processamento dos mesmos - mediante técnicas de geoprocessamento que permitiram o cruzamento dos dados e a disponibilização de novas informações, conforme a Figura 2 ilustra. O SIG foi constantemente realimentado conforme novas informações eram obtidas.

O banco de dados criado na etapa 1 conteve informações sobre a planialtimetria e a hidrografia, as quais, mediante técnicas de geoprocessamento, geraram mapas de hipsometria, declividade e modelo numérico do terreno (MNT) da área de estudo. A compilação e o processamento destas informações, aliadas aos demais levantamentos 
realizados em trabalhos de campo, etapa 2, possibilitaram diagnósticos mais apurados da propriedade. Com isso, o SIG foi incrementado com informações da forma do relevo e das nascentes da propriedade, as quais geraram o mapa das Áreas de Proteção Permanente (APP's) e o de compartimen- tação do relevo. A prévia compartimentação do relevo em cinco patamares, conforme Quadro 1 e Figura 1, facilmente perceptíveis pelo declínio da altimetria no sentido nordeste para sudoeste, foram subsídio para a posterior definição das Unidades de Paisagem.

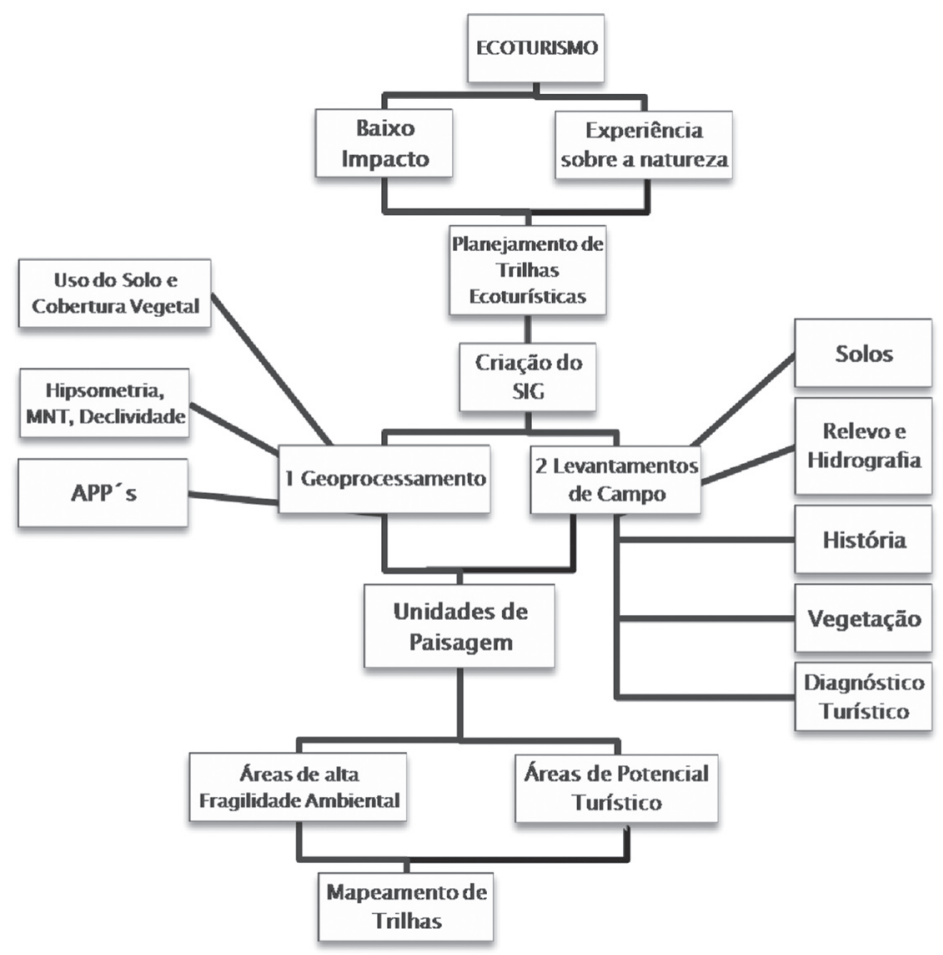

Figura 2 - Fluxuograma da metodologia de trabalho.

\section{Quadro 1 - Compartimentação do relevo}

\begin{tabular}{|l|c|c|l|}
\hline \multicolumn{1}{|c|}{ Patamar } & $\begin{array}{c}\text { Elevação } \\
\text { Aproximada }\end{array}$ & $\begin{array}{c}\text { Declividade } \\
\text { Aproximada }\end{array}$ & \multicolumn{1}{|c|}{$\begin{array}{c}\text { Características } \\
\text { Principais }\end{array}$} \\
\hline Patamar 1, Cotas Superiores & 790 a 840 metros & 0 a $20 \%$ & $\begin{array}{l}\text { Topo superior do } \\
\text { morro }\end{array}$ \\
\hline Patamar 2, Morros & 760 a 790 metros & 0 a $20 \%$ & $\begin{array}{l}\text { Relevo em processo } \\
\text { de dissecação }\end{array}$ \\
\hline $\begin{array}{l}\text { Patamar 3, Encostas de } \\
\text { Vales }\end{array}$ & 711 a 760 metros & 20 a $50 \%$ & $\begin{array}{l}\text { Encostas de vales } \\
\text { encaixados }\end{array}$ \\
\hline Patamar 4, Fundo de Vales & 677 a 711 metros & 0 a $20 \%$ & $\begin{array}{l}\text { Fundo de vales } \\
\text { encaixados }\end{array}$ \\
\hline Patamar 5, Encostas & 410 a 677 metros & 30 a $100 \%$ & $\begin{array}{l}\text { Encosta do vale } \\
\text { formado pela } \\
\text { dissecação do Arroio } \\
\text { Caracol }\end{array}$ \\
\hline
\end{tabular}

Fonte: KROEFF, 2007.

Já a análise de satélite de alta resolução QuickBird resultou em informações sobre o uso do solo e a cobertura vegetal, as quais foram aprofundadas em campo, com a verificação das espécies vegetais predominantes. As demais informações coletadas em campo diziam respeito à história de ocupação da região e especificamente da propriedade. Também se realizou um diagnóstico turístico regional, para se verificar os pontos turísticos principais de Canela e as atividades desenvolvidas em cada um, a fim de se desenvolver uma atividade ecoturística diferenciada no Ecoparque, que envolvesse mais contato com o ambiente e não apenas a contemplação.

\section{Análise dos resultados}


As Unidades de Paisagem foram delimitadas com base na forma do relevo e nos processos atuantes; pelos patamares 1 e 2 do relevo terem essas características muito semelhantes, esses foram unidos em uma só unidade. Posteriormente, cada unidade foi classificada quanto ao tipo de solo e de vegetação predominante. De acordo com essas informações, foi possível avaliar a potencialidade turística de cada unidade e a fragilidade ambiental - mediante a adaptação da metodologia proposta por Ross (1994) e Donha et al (2006), cruzou-se as informações declividade, solos, processos atuantes, áreas de preservação permanente e uso do solo e cobertura vegetal. Desta forma, quatro Unidades de Paisagem foram definidas, cada qual com características específicas. Conforme o que se demonstra no Quadro 2, as áreas de alto potencial turístico são aquelas onde o campo de visão é amplo, logo, as que proporcionam pontos com vista para as escarpas e os vales, fato que está associado à geomorfologia local.

O mapeamento das trilhas ecoturísticas buscou englobar as áreas de elevado potencial turístico e evitar as áreas de alta fragilidade ambiental. Com isso, considerou-se relevante mapear uma trilha de extensão mediana que englobasse as três primeiras Unidades de Paisagem e uma trilha de curta extensão que explorasse a Unidade de Paisagem 4 - Escarpa. A primeira, com aproximadamente $4,6 \mathrm{~km}$, foi denominada Trilha do Gato Preto por ter como ponto alvo o Morro do Gato Preto; e a segunda, com $2 \mathrm{~km}$ de extensão, Trilha dos Mirantes, pelos atrativos principais serem os mirantes para o Vale da Lajeana existentes na UP4. O traçado proposto para ambas é circular, a fim de atenuar o impacto de pisoteio, que gera a compactação do solo, e também para buscar manter a atenção do turista durante todo o percurso, uma vez que as atratividades não se repetirão.

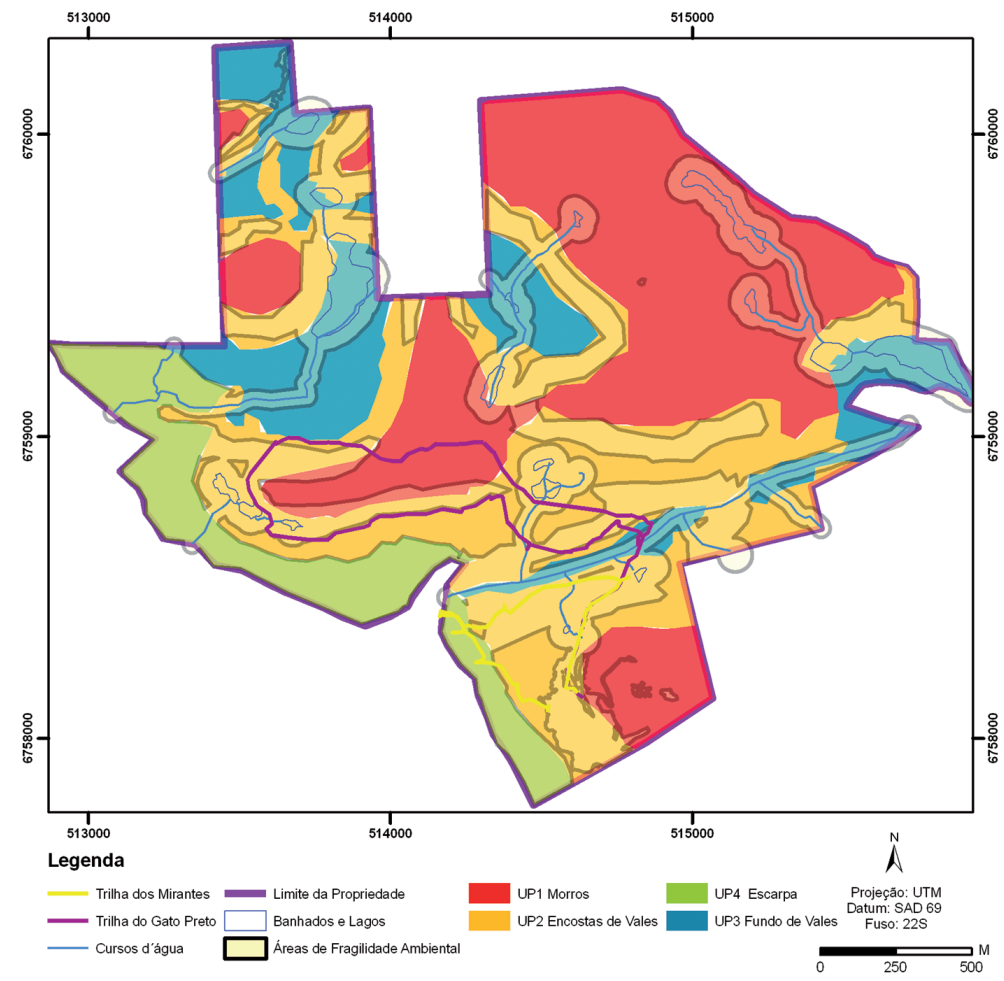

Quadro 2 - Características das Unidades de Paisagem (UP) da Propriedade do Ecoparque

Figura 3 - Mapa de Unidades de Paisagem, Fragilidade Ambiental e Trilhas Ecoturísticas 


\begin{tabular}{|c|c|c|c|c|c|}
\hline UP & PROCESSOS & SOLO & VEGETAÇÃO & Potenciais Turísticos & $\begin{array}{l}\text { Fragilidade } \\
\text { Ambiental }\end{array}$ \\
\hline $\begin{array}{l}\text { UP1 } \\
\text { Morros }\end{array}$ & $\begin{array}{c}\text { Morfo- } \\
\text { genéticos }\end{array}$ & $\begin{array}{l}\text { Cambissolos } \\
\text { húmicos } \\
\text { alumínicos }\end{array}$ & $\begin{array}{l}\text { Caracteriza-se pelo } \\
\text { maior } \\
\text { distanciamento das } \\
\text { árvores. } \\
\text { Predominantemente } \\
\text { vegetação em } \\
\text { estado avançado de } \\
\text { regeneração, matas } \\
\text { de araucária e pinus } \\
\text { plantadas. }\end{array}$ & $\begin{array}{l}\text { Contemplação da vista } \\
\text { para a região nas cotas } \\
\text { mais altas dos morros, } \\
\text { mediante instalação de } \\
\text { mirantes, e trilhas } \\
\text { interpretativas com } \\
\text { enfoque para os } \\
\text { processos ambientais de } \\
\text { regeneração da vegetação } \\
\text { - destaque para espécies } \\
\text { nativas e plantadas - e } \\
\text { histórico de ocupação do } \\
\text { uso do solo. }\end{array}$ & Baixa \\
\hline $\begin{array}{l}\text { UP2 } \\
\text { Encostas } \\
\text { de Vales }\end{array}$ & $\begin{array}{l}\text { Morfo- } \\
\text { genéticos }\end{array}$ & $\begin{array}{l}\text { Neossolos } \\
\text { litólicos } \\
\text { distróficos e } \\
\text { Cambissolos } \\
\text { húmicos } \\
\text { alumínicos }\end{array}$ & $\begin{array}{l}\text { Caracteriza-se pelo } \\
\text { menor } \\
\text { distanciamento das } \\
\text { árvores e maior } \\
\text { desordenamento das } \\
\text { mesmas. } \\
\text { Predominantemente } \\
\text { vegetação em } \\
\text { estado avançado de } \\
\text { regeneração, matas } \\
\text { de araucária } \\
\text { plantadas. }\end{array}$ & $\begin{array}{l}\text { Contemplação da vista } \\
\text { para os vales da } \\
\text { propriedade nas áreas } \\
\text { mais declivosas e das } \\
\text { pequenas quedas d'água e } \\
\text { trilhas interpretativas com } \\
\text { enfoque para os } \\
\text { processos ambientais - } \\
\text { destaque para espécies } \\
\text { nativas e plantadas - e } \\
\text { histórico de ocupação do } \\
\text { uso do solo. }\end{array}$ & Média a Alta \\
\hline $\begin{array}{l}\text { UP3 } \\
\text { Fundos de } \\
\text { Vales }\end{array}$ & $\begin{array}{l}\text { Pedo- } \\
\text { genéticos }\end{array}$ & $\begin{array}{l}\text { Latossolos } \\
\text { bruno } \\
\text { alumínico } \\
\text { câmbico }\end{array}$ & $\begin{array}{l}\text { Vegetação } \\
\text { característica de } \\
\text { ambientes úmidos, } \\
\text { grande presença de } \\
\text { xaxins. }\end{array}$ & $\begin{array}{l}\text { Contemplação de } \\
\text { espécies raras e em } \\
\text { extinção, com destaque } \\
\text { para os xaxins. }\end{array}$ & Alta \\
\hline $\begin{array}{l}\text { UP4 } \\
\text { Escarpa }\end{array}$ & $\begin{array}{l}\text { Morfo- } \\
\text { genéticos }\end{array}$ & $\begin{array}{l}\text { Neossolos } \\
\text { litólicos } \\
\text { distróficos }\end{array}$ & $\begin{array}{l}\text { Resquícios de } \\
\text { vegetação nativa. }\end{array}$ & $\begin{array}{l}\text { Contemplação da vista } \\
\text { para o Vale da Lajeana, } \\
\text { atividades de turismo de } \\
\text { aventura e trilhas } \\
\text { interpretativas com } \\
\text { enfoque para os } \\
\text { processos ambientais. }\end{array}$ & Alta \\
\hline
\end{tabular}

Fonte: KROEFF, 2007

O traçado das trilhas não evitou por completo as áreas de fragilidade ambiental, principalmente por elas coincidirem com as áreas de maior potencial turístico. Porém, o formato circular das trilhas e o acompanhamento das curvas de nível impedirão impactos ambientais mais expressivos. Além disso, ações de mitigação dos impactos negativos causados pelos ecoturistas foram sugeridas, especificamente, para as áreas de maior fragilidade ambiental. De maneira geral, também foram propostas diretrizes ao manejo estratégico do ecoturismo nas trilhas.

\section{Referências bibliográficas}

COSTA, N. M. C. da. e XAVIER DA SILVA, J. Geoprocessamento Aplicado à Criação de Planos de Manejo: O Caso do Parque Estadual da Pedra Branca/RJ. In: Geoprocessamento \& Análise ambiental: aplicações/Jorge Xavier da Silva, Ricardo Tavares Zaidan (organizadores). Rio de Janeiro: Bertrand Brasil, 2004. DONHA, Annelissa; SOUZA, Luiz C. de P. \& SUGAMOSTO, Maria L. Determinação da fragilidade ambiental utilizando técnicas de suporte à decisão e SIG. R. Bras. Eng. Agríc. Ambiental, v.10, n.1, p.175-181, 2006. Disponível em: www.scielo.br/pdf/rbeaa/ v10n1/v10n1a26.pdf, acesso em 20 de outubro de 2007.

FENNELL, D. A. Ecoturismo - uma introdução. São Paulo: Contexto, 2002. 281p.

GUERRA, Antonio José Teixeira e MARÇAL, Mônica dos Santos. Geomorfologia ambiental. Rio de Janeiro: Bertrand Brasil, 2006. em 20 de outubro de 2007.

KROEFF, Lia Lutz. Planejamento de Trilhas Ecoturísticas na Propriedade do Ecoparque, em Canela/RS. Universidade Federal do Rio Grande do Sul, UFRGS, Instituto de Geociências, Departamento de Geografia. Trabalho de Graduação em Geografia, 2007.

OLIVEIRA, M. O. \& GRIFFITH, J. J. Levantamento dos recursos visuais do Parque Florestal Estadual do Rio Doce. In: Universidade Federal de Viçosa. Plano Diretor do Parque Florestal Estadual do Rio Doce. Viçosa: Departamento de Engenharia Florestal/Instituto Estadual de Florestas de Minas Gerais, vol. 1, p. 84-92, 1987.

ROSS, J. L. S. Análise empírica da fragilidade dos ambientes naturais e antropizados. Revista do Departamento de Geografia. n. 8, p. 63-74, 1994.

SPÖRL, Christiane. Análise da fragilidade ambiental relevosolo com aplicação de três modelos alternativos nas altas bacias do Rio Jaguari-Mirim, Ribeirão do Quartel e Ribeirão da Prata. Dissertação apresentada à Faculdade de Filosofia, Letras e Ciências Humanas na USP. São Paulo, 2001. Disponível em: http://www.teses.usp.br/teses/disponiveis/8/8135/tde18012002-225147/, acesso em 09 de julho de 2007.

The International Ecotourism Society (TIES). Disponível em: www.ecotourism.org/, acesso em 20 de outubro de 2007.

IBAMA. IEB - Instituto de Ecoturismo do Brasil. Disponível em: http://www.ibama.gov.br/revista/apresentação.htm, acesso 